\title{
TESTE DE JOGABILIDADE E AVALIAÇÃO DE UM JOGO DIGITAL SOBRE SINTOMAS DO ACIDENTE VASCULAR CEREBRAL E PROCEDIMENTOS DE EMERGÊNCIA
}

\author{
José Guilherme Santa Rosa, D.Sc. \\ Programa de Pós-Graduação em Design - Universidade Federal do Rio Grande do Norte \\ santarosa@cchla.ufrn.br \\ Carlos Dias Limeira \\ Mestrando em Design - Universidade Federal do Rio Grande do Norte \\ carloscafedias@gmail.com \\ João Bosco de M. Santos \\ Graduando em Design - Universidade Federal do Rio Grande do Norte \\ jbsantosxd@hotmail.com \\ Mário Sérgio G. Filgueira \\ Graduando em Design - Universidade Federal do Rio Grande do Norte \\ mariodesigner@live.com \\ Cínthia Kulpa, M.Sc. \\ Departamento de Design e Expressão Gráfica - Universidade Federal do Rio Grande do Sul \\ cinthia.kulpa@gmail.com \\ André Luís Santos de Pinho, D.Sc. \\ Departamento de Estatística - Universidade Federal do Rio Grande do Norte \\ pinho@ccet.ufrn.br \\ Antônio Pereira Júnior, D.Sc. \\ Instituto do Cérebro - Universidade Federal do Rio Grande do Norte \\ squareshorts@gmail.com
}

Resumo: $O$ trabalho apresenta os testes de jogabilidade realizados com um jogo digital destinado ao esclarecimento e conscientização de préadolescentes sobre os principais sintomas do Acidente Vascular Cerebral (AVC) e procedimentos de emergência que devem ser adotados ao se depararem com o quadro. O citado jogo foi testado pelos estudantes de uma escola pública no município de Natal, Rio Grande do Norte e de uma escola pública em Alvorada, no Rio Grande do Sul. As avaliações apresentaram as diferenças entre a percepção dos pré-adolescentes e a 
eficiência na memorização do número do Serviço de Atendimento Móvel de Urgência (SAMU) do jogo digital desenvolvido e de uma animação divulgada pelo Ministério da Saúde além da diferença percebida nos resultados obtidos dos testes realizados com estudantes das duas cidades. Concluiu-se que, tanto o jogo digital quanto a animação apresentaram o mesmo nível de eficiência no que diz respeito à retenção/memorização do número da SAMU e dos principais sintomas do AVC, contudo, de modo geral, os préadolescentes manifestaram predileção pelo jogo, em virtude, principalmente, pelo nível de interatividade.

Palavras-chave: Design, Jogos Digitais, Acidente Vascular Cerebral.

\begin{abstract}
The paper presents the tests performed gameplay with a digital game aimed at clarifying and awareness of pre-teens about the main symptoms of Stroke and emergency procedures to be adopted when faced with scenario. The aforementioned game was tested and evaluated in students from a public school in Natal, Rio Grande do Norte and a public school in Alvorada, Rio Grande do Sul. The results presented differences between the perceptions of pre-teens and efficiency in memorizing the number of medical emergency of digital game developed and an animation released by the Ministry of Health besides the perceived in the results of tests conducted with students from two towns difference. It was concluded that both the game and digital animation exhibited the same level of efficiency in regard to the retention/storage of the emergency number and the main symptoms of stroke, but, in general, pre-teens expressed preference for game, due mainly by the level of interactivity.
\end{abstract}

Key-words: Design, Digital Game, Stroke.

\title{
1. INTRODUÇÃO
}

O Acidente Vascular Cerebral (AVC) é uma doença cerebrovascular causa de metade das mortes por ano no mundo e, no Brasil, representa a primeira causa de morte e incapacidade (BRASIL, 2011). Por se tratar de uma urgência médica, ao serem detectados os sintomas em uma pessoa, a ajuda deve ser acionada o mais rápido pelo número 192, do Serviço de Atendimento Móvel de Urgência (SAMU), aumentando as chances de recuperação sem sequelas do acometido.

Para alertar a população sobre a doença e os seus sintomas, assim como divulgar o número do SAMU, são desenvolvidas campanhas educativas através de cartilhas, animações e vídeos. Esse mesmo material educativo também é destinado a crianças e adolescentes, mas acredita-se que a utilização de um jogo disponível na Internet desenvolvido para esta finalidade, em razão do seu caráter interativo e imersivo poderia atrair a atenção deste público-alvo e ajudar na retenção das informações apresentadas, despertando maior interesse e sensibilidade pelo assunto e assim causar um comportamento multiplicador. 
Com isso, busca-se apresentar neste trabalho, os testes de jogabilidade realizados com pré-adolescentes, de um jogo digital sobre o AVC, que tem por objetivo esclarecer e conscientizar os mesmos dos principais sintomas e procedimentos de emergência que devem ser adotados ao se depararem com o quadro. Para tanto, serão abordados os conceitos envolvidos neste trabalho, a fim de possibilitar obter um entendimento maior sobre os parâmetros utilizados na pesquisa.

\section{JOGOS DIGITAIS NA EDUCAÇÃO}

Diferentemente da animação tradicional e de outros tipos de jogos, o jogo digital compreende uma relação ativa entre jogador e máquina, em que a ideia de representação está fortemente presente na figura do avatar controlado pelo jogador, que imerge na imagem interativa do game. Para Johnson (2005) os jogos digitais fazem parte dos atuais meios de comunicação inteligentes que acabam por estimular e desenvolver as habilidades cognitivas. Os jogos também são causadores de impactos psíquicos, culturais, científicos e educacionais (VENTURELLI e MACIEL, 2008). Mais do que simples entretenimento, os jogos digitais estimulam o aprendizado de forma ativa, podendo serem utilizados na educação como ferramentas de apoio ao ensino, motivando o aprendizado dos jogadores enquanto se divertem, como acontece com os jogo sérios (serious game) com conteúdos e tecnologias que visam cumprir objetivos de ensino com públicos específicos.

\section{MÉTODOS E TÉCNICAS}

O presente trabalho contou com a colaboração de professores, alunos de pósgraduação e de graduação. Com o objetivo de ensinar pré-adolescentes a diagnosticarem os sintomas do AVC e memorizarem o número do SAMU, foi desenvolvido um jogo eletrônico para computadores desktop e notebooks, pelo Laboratório de Ergodesign de Interfaces e Usabilidade (LEXUS/UFRN), testado e avaliado por alunos pré-adolescentes de escolas públicas de Natal/RN e de Alvorada/RS, sendo distribuído gratuitamente na Internet uma versão protótipo do mesmo intitulada "Esquadrão 192" em que o jogador assume o papel do protagonista (Agente $X$ ) com a missão de salvar um idoso que apresenta algum dos sintomas do AVC pela orla da praia, cenário no qual a história se desenrola, discando para o SAMU por meio do 192. Caso não saiba ou disque incorretamente o número, o próprio jogo explica quais os sintomas e o respectivo número de emergência que deve ser acionado (Figura 1) podendo o jogador voltar ao início do jogo para tentar chegar ao final da aventura. Para controlar o avatar do personagem no jogo, o jogador deverá utilizar as setas direcionais do teclado, assim como o botão direito do mouse para escolher as opções na interface do game. Uma vez finalizada a versão protótipo do jogo (Figura 1), percebeu-se a necessidade em realizar testes de jogabilidade com o público-alvo a fim de verificar se os parâmetros de jogo estavam adequados às expectativas e objetivos dos desenvolvedores. 


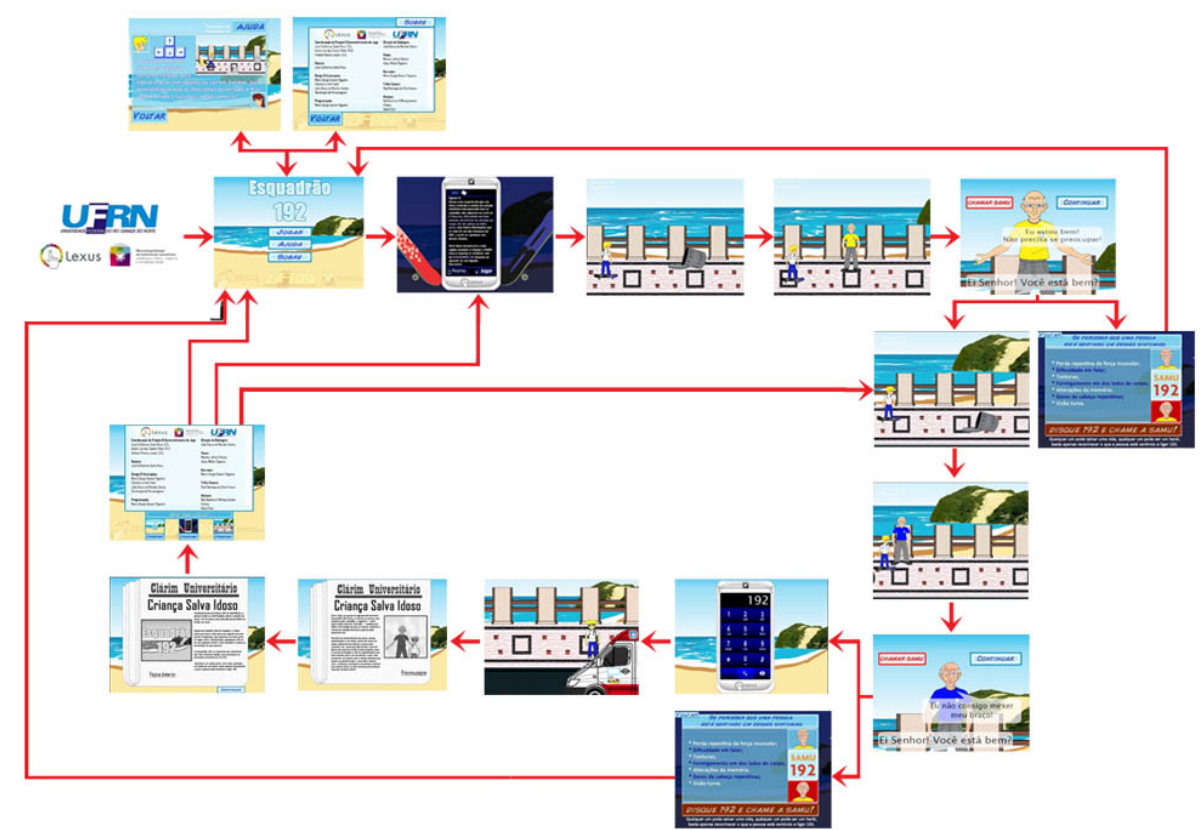

Figura 1 - Fluxograma apresentando as telas representativas da versão protótipo do jogo. Fonte: Elaborada pelos autores, com base na pesquisa realizada.

Destaca-se que a partir dos resultados obtidos e das conclusões levantadas com a versão protótipo, o jogo final poderá ser implementado e distribuído em campanhas de conscientização e sensibilização a respeito do Acidente Vascular Cerebral (AVC). Além da versão protótipo do jogo desenvolvido pelo LEXUS/UFRN, nos testes com usuários foi utilizada uma animação sobre os sinais e sintomas de alerta do AVC, realizada pela Sociedade Brasileira de Doenças Cerebrovasculares e utilizada pelo Ministério da Saúde na Campanha da Semana Nacional de Combate ao AVC, com duração aproximada de três minutos (ASSOCIAÇÃO BRASIL AVC, 2011).

A pesquisa foi aplicada em duas escolas públicas brasileiras, sendo uma localizada na cidade de Natal, Rio Grande do Norte (Escola Municipal Juvenal Lamartine) e outra localizada na cidade de Alvorada, Rio Grande do Sul (Escola Estadual de Ensino Médio Carlos Drummond de Andrade), entre 26 de março a 11 de abril de 2014. Ao todo participaram da pesquisa 39 pré-adolescentes, sendo 20 de Natal e 19 de Alvorada, de ambos os sexos, na faixa-etária de 8 a 13 anos, com autorização dos responsáveis por meio da assinatura do Termo de Consentimento Livre e Esclarecido (TCLE). 


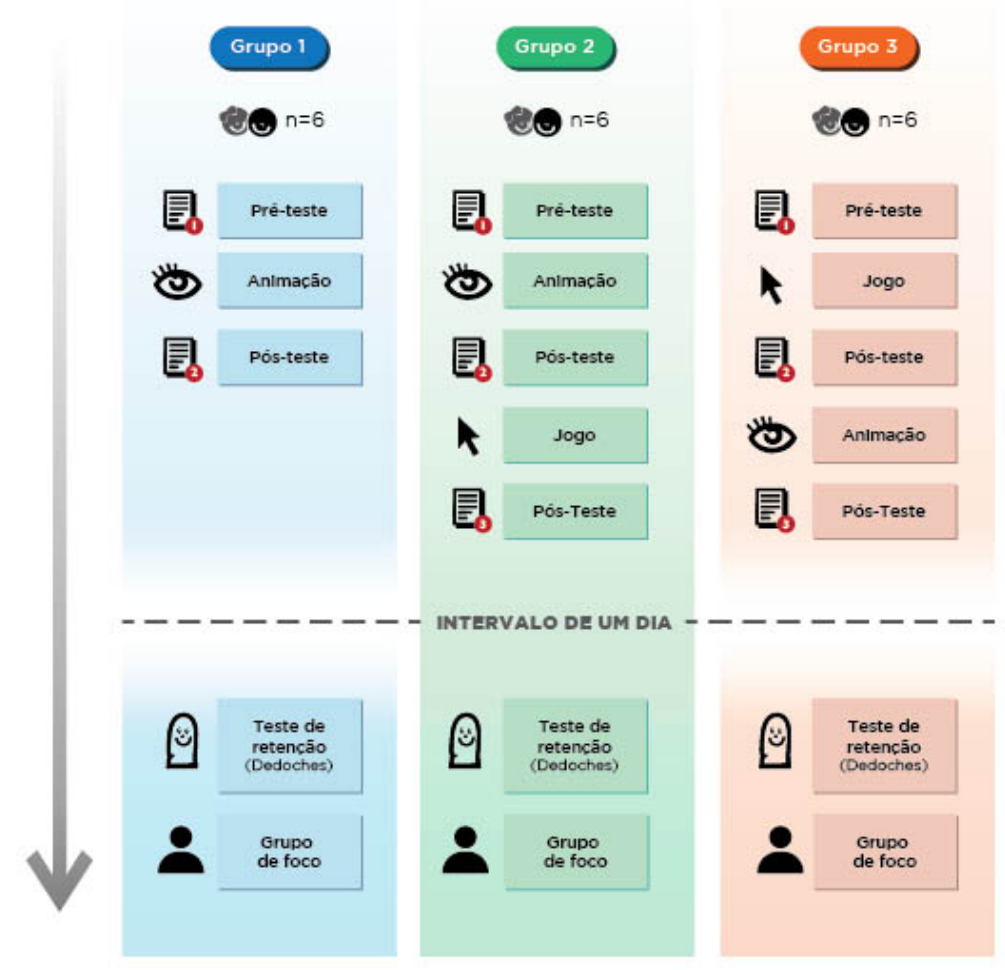

Figura 2 - Quadro metodológico apresentando grupos de sujeitos, fases e técnicas da pesquisa. Fonte: Elaborada pelos autores, com base na pesquisa realizada.

Por critério metodológico, os mesmos foram divididos em três grupos (figura 2):

- Grupo 1 (Animação) em que os participantes assistiam o vídeo animado;

- Grupo 2 (Animação e Jogo) com os participantes submetidos a animação e ao jogo (nessa ordem);

- Grupo 3 (Jogo e Animação) com os participantes submetidos ao jogo e animação (nesta ordem).

A aplicação dos testes obedeceu uma organização. No primeiro dia, foram realizadas as seguintes etapas:

1. Pré-teste, uma entrevista oral com os participantes a respeito de suas preferências e conhecimento sobre o SAMU;

2. Apresentação da animação e/ou jogo de acordo com o grupo;

3. Pós-teste, entrevista oral na qual o participante foi perguntado acerca de sua experiência com a(s) mídia(s) apresentada(s) e com o número do SAMU.

No segundo dia, após um intervalo de 24 horas, foram conduzidos:

4. Teste de retenção, teatro interativo com bonecos de dedo (dedoches) no qual o participante foi perguntado acerca do número do SAMU;

5. Teste de preferência, observação do comportamento dos sujeitos a partir da disponibilização de computadores com a animação e com o jogo; 
6. Grupo Focal, entrevista em grupo para levantar sugestões de melhorias para o jogo apresentado.

Destaca-se que antes da aplicação dos testes definitivos, foi realizado um piloto com quatro pré-adolescentes, todos com 10 anos de idade, que permitiu à equipe de pesquisa realizar alguns ajustes necessários para o aperfeiçoamento dos instrumentos e procedimentos apresentados.

No Pré-teste (Figura 3), os participantes responderam de forma oral: (1) Você costuma ver desenhos animados na televisão?; (2) Você costuma jogar no computador ou videogame?; (3) Você sabe ligar de um telefone celular?; (4) Você sabe o que é o SAMU?, visando extrair informações do contexto cultural dos pré-adolescentes. Após o pré-teste, os participantes foram apresentados ao jogo e/ou animação (Figuras 3 e 4), de acordo com um dos três grupos ao qual foram inseridos.

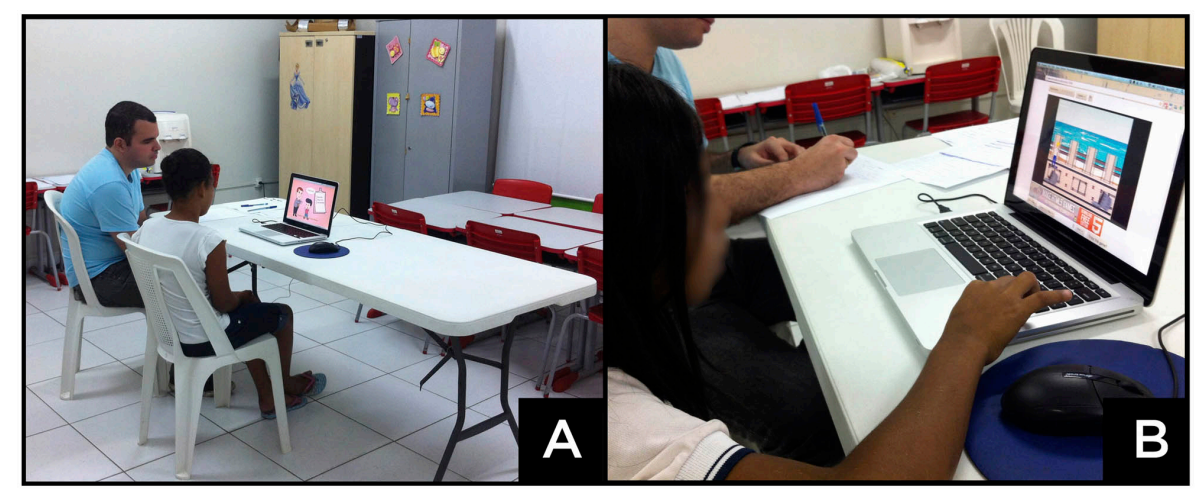

Figura 3 - Participante da escola em Natal assistindo a animação (A) e interagindo com o jogo (B). Fonte: Autores da pesquisa realizada.

Após o contato com a animação e/ou jogo foi realizado o Pós-teste (Figura 4a), em que participantes relatam a sua experiência com a respectiva(s) mídia(s) apresentada(s), respondendo a pergunta "Você gostou? Porque" e avaliando os seus humores (podendo apontar mais de um humor) através do uso da escala visual Pick-A-Mood (PAM) baseada em desenhos animados e que expressam oito tipos de humor (negativos e positivos) mais um estado neutro (Figura 4b). O instrumento desenvolvido por pesquisadores da Universidade de Delft, Holanda, é validado pela comunidade acadêmica e está disponível gratuitamente para uso não-comercial sob a licença Creative Commons. Segundo Desmet et al. (2002), para a medição de humores são utilizados, tradicionalmente, questionários e escalas verbais, que além de cansativas para os entrevistados são sensíveis a diferenças culturais pelas grafias dos termos. Esses problemas são contornados com o uso de escalas visuais tornando o teste rápido, intuitivo e estimulante. Para Csikszentmihaly e Hunter (2003 apud DESMET, 2002) o humor é uma fonte de informação mais estável do que as emoções no monitoramento do bem-estar das pessoas, sendo altamente relevante no design dada a sua capacidade de influenciar nossos comportamentos e atitudes, além de auxiliar em nossas interações sociais, como ser solidário com o próximo (GARDNER, 1985). 


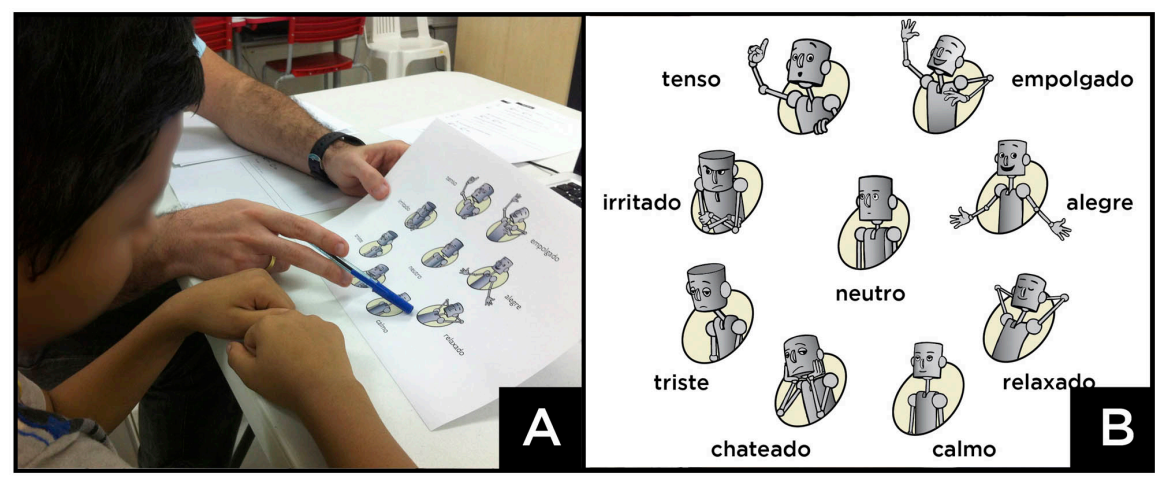

Figura 4 - Pós-teste, na escola em Natal (A), utilizando a escala visual PAM com o personagem robô (B). Fonte: Autores da pesquisa realizada.

Na etapa seguinte, após intervalo de 24 horas, ocorreu o Teste de retenção (Figura 5a), que teve como propósito medir o nível de retenção das informações transmitidas pelo jogo digital desenvolvido e pela animação apresentada, em que os sujeitos participaram de um teatro de bonecos de dedo (dedoches) interagindo com os personagens do jogo encenados.

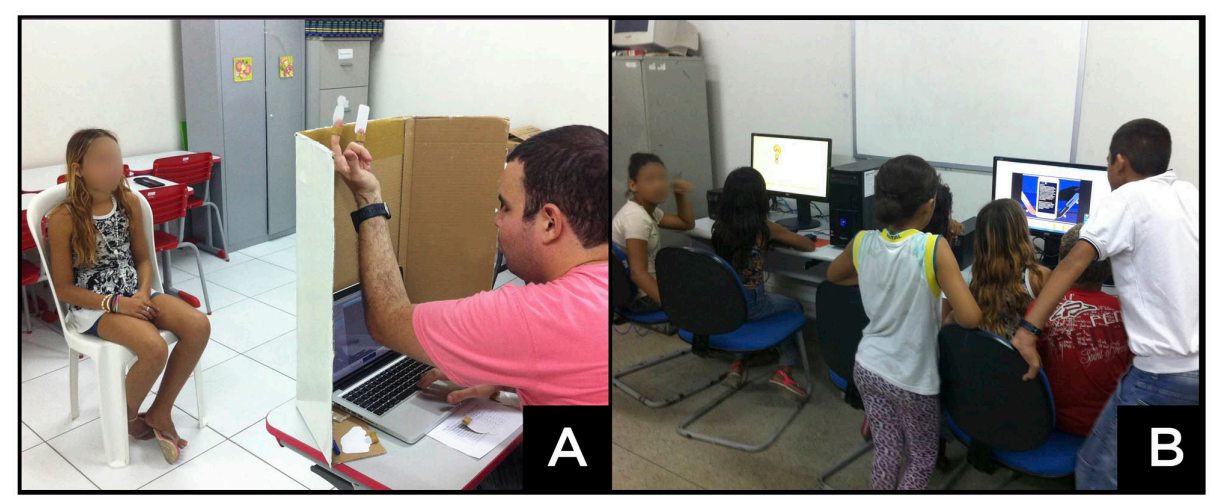

Figuras 5 - Teste de Retenção (A) e Teste de Preferência na escola em Natal (B). Fonte: Autores da pesquisa realizada.

Após o Teste de retenção com o uso dos dedoches, ocorreu o Teste de preferência (Figura 5b). Este teste consistiu na observação do comportamento dos participantes a partir da disponibilização de dois computadores desktop, sendo um apresentando o jogo e outro apresentando a animação. Os pesquisadores deixaram as crianças livres por aproximadamente 10 minutos e observaram a distribuição e suas preferências a respeito dos dois recursos apresentados bem como os comentários e diálogos a respeito. Destacase que este momento de interação inicial teve como finalidade deixar as crianças mais à vontade para a realização da atividade de grupo focal e ao mesmo tempo propiciar mais um contato com os recursos antes dar início a próxima etapa.

Em seguida, logo após o teste de retenção realizou-se o Grupo focal, que consistiu numa entrevista mais aprofundada feita em grupo, com o objetivo de levantar considerações mais aprofundadas e sugestões de melhoria para o jogo pelos participantes. Para esta etapa, a escolha do ambiente, materiais e procedimentos adotados procurou seguir as orientações de aplicação trazidas pela literatura sobre o 
tema, em que utilizou-se de: uma mesa grande, cadeiras, um notebook, um projetor multimídia, além do material de registro (gravador, máquina fotográfica, papel e caneta). A realização das sessões de Grupo focal permitiu a discussão a partir do roteiro: 1) Qual dos dois foi mais interessante? Porque?; 2) o que a animação tem de "legal"? (desenhos, cor, música, fala, etc.); 3) o que o jogo tem de legal?; 4) Como o jogo poderia ser melhorado. Seria mais legal se tivesse...; 5) Os personagens são bonitos?; 7) e a música do jogo? 9) Se pudéssemos inventar outro jogo para divulgar os sintomas do AVC e o número do SAMU como poderia ser feito?; 10: Que tipo de jogo, personagem, cenário, música? Destaca-se, também, que para a realização desta etapa os pesquisadores providenciaram o registro da atividade em áudio e consideraram as seguintes condutas: a) chamar as crianças pelo nome de modo a facilitar a análise dos dados; b) propiciar a todas as crianças a oportunidade de falar; c) fotografar os momentos principais da atividade de grupo focal; d) anotar os pontos e falas principais; e) elaborar perguntas pertinentes a situação que não estejam presentes no roteiro de discussão previamente estabelecido.

\section{RESULTADOS}

\subsection{Escola em Natal}

$\mathrm{Na}$ etapa definitiva dos testes realizados em Natal, participaram 14 préadolescentes. No primeiro dia de testes, as entrevistas do Pré-teste foram realizadas de forma individual com cada participante, que em sua totalidade disseram assistir desenhos animados e jogar algum tipo de jogo digital. Quando perguntados acerca do SAMU, 8 afirmaram saber o que é, mas apenas quatro responderam corretamente o número 192. Durante a apresentação da animação, todos assistiram com bastante atenção. Quando perguntados se gostaram, todos afirmaram que sim, destacando a música, o desenho dos personagens, respondendo que assistiriam novamente. Os humores mais relatados após a visualização foram: alegria (9) e empolgação (5). Observou-se que um participante disse se sentir ao mesmo tempo "triste", por conta do personagem doente, e "alegre", por causa da música "animada". Durante a interação com o jogo, observou-se que apesar de enfrentarem problemas com o nível de dificuldade do jogo, todos os participantes afirmaram que não consideraram jogo difícil, o que corrobora para a importância do fator desafio nos jogos. Muitos não conseguiram acionar a SAMU inicialmente, tendo que jogar novamente o game, o que indica a vontade em permanecer desviando dos obstáculos com o skate. Observou-se, também, que após terem jogado, grande parte dos participantes disseram ter gostado de salvar pessoas, confirmando, o que aponta Seligman (2004) ser uma atitiude positiva e gratificante em humanos, possibilitada pelo game que acabou por gerar o estado de flow nos jogadores, um estado mental de total imersão que podemos alcançar em determinadas atividades, obtendo respostas e sendo gratificadas pelas mesmas (CSIKSZENTMIHALYI, 1999). Quando perguntados se haviam gostado, todos os 14 afirmaram que sim, respondendo que jogariam novamente, destacando-se alguns pontos como o personagem com skate, o desafio de desviar dos obstáculos, a discagem com o telefone, o cenário e a narração do jogo. Os humores relatados em maior número após a interação foram alegria (8) e empolgação (5). Observou-se que um participante se sentiu ao mesmo tempo "triste", por conta do 
personagem doente, e "alegre", pois pôde salvá-lo. Alguns participantes tinham dificuldade de leitura ou disseram desconhecer a palavra "turva", reforçando o que aponta Knowlers (2012) acerca da importância da narração sonora em jogos, que além de fornecer feedback à interação e reforçar as ações da interface, provê informações essenciais para deficientes visuais, analfabetos e crianças ainda não alfabetizadas. Por fim, foi observado também que quando perguntados acerca de uma preferência (o jogo ou a animação) todos os participantes, com exceção de dois, afirmaram ter gostado mais do jogo, alegando estarem no controle das ações. Ainda no primeiro dia, posteriormente ao contato dos participantes com a animação e/ou jogo, no Pós-teste, quando perguntados novamente acerca do número do SAMU, todos exceto um responderam corretamente.

Após o intervalo de 24 horas, no Teste de retenção com os dedoches, foi mantido o mesmo resultado ao ser feita a mesma pergunta anterior. No Teste de preferência, observou-se uma grande predileção pelo jogo no comportamento dos participantes em grupo. E ao término do segundo dia, o Grupo focal destacou alguns pontos além dos que já foram anteriormente observados, destacando-se:

- as meninas consideraram a animação mais colorida;

- alguns gostaram do fato da animação apresentar personagens idosos de sexos e desenhos variados;

- todos os participantes (exceto um) afirmaram que a música agitada ajuda no jogo e que o desenho dos personagens poderia ser melhorado.

\subsection{Escola em Alvorada}

$\mathrm{Na}$ etapa definitiva dos testes realizados na escola em Alvorada, participaram 19 pré-adolescentes. No primeiro dia de testes, o questionário foi respondido individualmente, sendo que todos os participantes afirmaram assistir desenhos animados, enquanto quatro destes responderam que não costumam jogar no computador ou videogame. Além disso, 18 participantes responderam saber o que é a SAMU, porém somente 15 souberam responder corretamente qual era o número da SAMU no Pré-teste. Este dado foi confirmado através do Grupo focal, quando através dos depoimentos dos participantes que sabiam o número da SAMU constatou-se que maioria deles ficavam com os avós enquanto os pais estão trabalhando. E, portanto, são orientados a procurarem a SAMU para eventuais emergências. No momento de apresentação da animação, os participantes se distraiam com frequência. Este fato pode estar relacionado com o barulho ocasionado pela transmissão simultânea da animação sem o auxílio dos fones de ouvido. Observou-se que após serem apresentadas as explicações sobre os sintomas do AVC e sobre como proceder neste caso (0:58 de animação), os participantes não queriam mais assistir a animação. Os participantes gostaram dos momentos em que apareciam os sintomas de AVC nas pessoas, relatando-os como engraçados. Dos 19 participantes, 15 gostaram da animação, sendo que alguns comentaram: "É um jeito divertido de aprender os sintomas do AVC", "Ajuda a lembrar o número do SAMU se divertindo", "Mostra se você machucar alguém você chama o SAMU", "É bom saber como é importante chamar o SAMU". Os humores relatados pelos participantes foram: alegre (8), empolgado (7), calmo (2), tenso (1) e neutro (1). Vários participantes pediram para marcar mais de um humor, após a primeira escolha, variando entre "relaxado", "triste" e "chateado". Na interação 
com o jogo participaram 16 pré-adolescentes, sendo que quatro participantes se mostraram inquietos com o texto explicativo no início do jogo, perguntando inclusive onde estava localizada a tecla de início do jogo, pois queriam passar direto para o jogo. Percebeu-se que muitos não entenderam quando perderam o jogo, pois eles continuavam jogando e chegavam a parar o jogo depois de um tempo, uma vez que percebiam que não "avançaram" no desafio. Além disso, no encontro com o personagem idoso do jogo, alguns se confundiram na ação que deveriam escolher, chamando o SAMU para o idoso que não apresentava os sintomas de AVC. Neste momento, o jogo encerrava (pois fizeram a escolha errada e perderam), mas os participantes não entendiam que teriam que recomeçar o jogo novamente, uma vez que não era apresentada a mensagem de "game over". Um participante conseguiu jogar todas as etapas do jogo em apenas dois minutos, comentando que conseguiu o feito devido à ter avançado mais rapidamente utilizando-se da seta da direita do teclado. Outra observação apontada, foi de que alguns participantes comentaram entre si, erroneamente, que era possível pular o obstáculo no percurso (não percebiam que o jogo reiniciava após a colisão). Nenhum participante perguntou se existia algum tutorial ou se havia objetivo de jogo. Dos 16 participantes, apenas um não gostou do jogo afirmando que "O percurso era repetitivo só mudava os objetos no caminho". Os humores relatados foram "empolgado", "alegre", "neutro" e "calmo".

No segundo dia de testes, no Teste de retenção com os dedoches, as perguntas foram respondidas adequadamente por todos os participantes ao mesmo tempo. No teste de preferências, observou-se que sete participantes, todos meninos, e apenas uma menina se dirigiram para o jogo (com a música de rock no fundo), enquanto os outros participantes (todas meninas) se dirigiram para a animação. Esta observação leva ao questionamento quanto ao estilo do jogo e da animação em relação às preferências, uma vez que o jogo possuía música no estilo rock e o protagonista é um menino, enquanto a animação tem desenho leve e a música é infantil. Já no teste de grupo focal, além de todos afirmarem que gostaram do jogo, eles destacaram alguns problemas a serem observados:

- não havia a possibilidade de escolher entre protagonista menino ou menina;

- falta de aviso nos momentos que o protagonista se choca com os obstáculos;

- a falta de opção de continuar de onde parou, quando o protagonista errava, tendo que iniciar o jogo desde o texto introdutório;

- a falta de complexidade e continuidade do jogo;

- não ter um cenário interativo e dinâmico;

- só ter um modo de locomoção para o protagonista;

\subsection{Recomendações}

Com estas observações, é possível identificar algumas modificações que levem à uma melhor jogabilidade, tais como:

- Dar ao jogador a possibilidade de escolher o sexo do protagonista (menino ou menina) assim como o modo de locomoção (skate, patins, patinete, bicicleta ou até ambulância) e música de fundo do jogo; 
- Aumentar a complexidade do jogo através de fases "levels", tempo de vida ou reação, assim como aumentar a velocidade do meio de locomoção conduzido pelo protagonista e dar continuidade à história;

- O jogo não deveria reiniciar após as colisões com os obstáculos encontrados no percurso, acrescentando feedback nos momentos em que o sprite do protagonista colide com o obstáculo, através de efeitos sonoros e visuais como "estrelinhas", "tela tremendo" ou "game over" para quando se perde o jogo;

- Permitir que o protagonista continue o jogo mesmo quando ele decidir chamar a SAMU para o personagem idoso que não tem os sintomas do AVC. Uma tela explicativa poderia informar qual a melhor escolha deveria ter sido feita, dando continuidade ao jogo;

- Propor um cenário mais interativo e mutante, podendo pular sobre os obstáculos e fazer manobras em rampas, podendo apresentar pessoas e barracas ao fundo;

- O jogador poderia ser recompensado com pontos ou moedas para as ações no decorrer da partida e que pudessem trocá-las por bônus (como roupas e acessórios).

\section{CONCLUSÃO}

Além de motivadores e desafiantes, os jogos digitais podem contribuir para o aprendizado, acima de tudo, de forma divertida, usando situações cotidianas para gerar reflexão e conhecimento em que os jogadores literalmente aprendem jogando. Concluiuse que, embora não tenha havido diferenças significativas entre a retenção dos conhecimentos considerando o jogo digital desenvolvido e a animação testada, a utilização de jogos digitais para fins educativos voltados à sensibilização e conscientização contribuiu tanto para a aceitação, quanto a imersão e engajamento dos pré-adolescentes, promovendo a identificação destes atores sociais no momento em que perceberam que podem assumir um certo controle da situação ao invés de exercer uma postura passiva diante da transmissão de informação, como no caso da visualização de animação com a mesma finalidade.

\section{REFERÊNCIAS}

ASSSOCIAÇÃO BRASIL AVC. SAMU 192 Sinais e sintomas de alerta de AVC: O que fazer?, 2011. Disponível em: <http://www.abavc.org.br/samu-192-sinais-e-sintomas-de-alertade-avc-o-que-fazer>. Acesso em: 25 abr. 2014.

BRASIL. Ministério da Saúde. Em 10 anos, País reduz em 32\% mortes por AVC. Portal Brasil, 2011. Disponível na internet por: <http://www.brasil.gov.br/saude/2011/11/redede-atencao-ao-avc- tera-reforco-de-r-437-milhoes>. Acesso em: 25 abr. 2014.

CSIKSZENTMIHALYI, Mihaly. A descoberta do fluxo. Rio de Janeiro: Rocco, 1999.

DESMET, P. M. A; VASTENBURG, M. H; VAN BEL, D.; ROMERO, N. PICK-A-MOOD: Development and application of a pictorial mood-reporting instrument. London: 8th International Conference on Design and Emotion, 2012.

JOHNSON, Steve. Surpreendente!: a televisão e o videogame nos tornam mais inteligentes. Rio de Janeiro: Elsevier, 2005. 
SALEN, Katie; ZIMMERMAN, Eric. Regras do jogo: fundamentos do design de jogos: principais conceitos: volume 1. São Paulo: Blucher, 2012.

SELIGMAN, Martin. Felicidade Autêntica: usando a nova psicologia positiva para a realização permanente. Rio de Janeiro: Objetiva, 2004.

VENTURELLI, Suzete; MACIEL, Mario Luiz Belcino. Imagem interativa. Brasília: Editora Universidade de Brasília, 2008.

\section{AGRADECIMENTOS}

Agradecemos à Jeana Magalhães, aos professores e às crianças da Escola Municipal Juvenal Lamartine (Natal, RN) e da Escola Estadual de Ensino Médio Carlos Drummond de Andrade (Alvorada, RS) assim como aos seus responsáveis e às Pró-Reitorias de PósGraduação e de Extensão da Universidade Federal do Rio Grande do Norte. 